\title{
TORNAR PRESENTE O AUSENTE: ESCRITA CRIATIVA E REFLEXÃO SOBRE DIREITOS HUMANOS
}

Ana Rüsche

Faculdade de Filosofia, Letras e Ciências Humanas da Universidade de São Paulo (FFLCH - USP),

São Paulo, SP - Brasil. <anarusche@gmail.com>

Laura D. M. Mascaro

Faculdade de Filosofia, Letras e Ciências Humanas da Universidade de São Paulo (FFLCH - USP),

São Paulo, SP - Brasil. Centro de Estudos Hannah Arendt, São Paulo, SP - Brasil.

<laura.mascaro@hannaharendt.org.br>

http://dx.doi.org/10.1590/0102-64450055-087/96

Buscaremos relatar aqui a experiência de um ciclo de oficinas de escrita criativa abordando o tema direitos humanos, organizado no ano de 2014, em duas edições ${ }^{1}$, pela cátedra Unesco de Educação para Paz, Direitos Humanos, Democracia e Tolerância. Esse ciclo de oficinas emprestou seu título de uma citação de Hannah Arendt no livro Men in dark times (Homens em tempos sombrios), "A narrativa revela o sentido sem cometer o erro de defini-lo"2 (Arendt, 1968, p. 105), tendo em vista que se baseou no pensamento da autora a respeito da narrativa, assim como das dimensões do pensar, do julgar e da vida política. Ressaltamos que o acesso a ambas as edições das oficinas era gratuito, em locais na área central da cidade de São Paulo.

Hannah Arendt considerava a experiência e o exemplo como fundamentais para o exercício do senso comum

\footnotetext{
1 A primeira edição das oficinas ocorreu no Centro Universitário Maria Antônia e a segunda na Faculdade de Direito da Universidade de São Paulo, contando com o apoio de sua Academia de Letras.

2 Tradução livre das autoras do original: "storytelling reveals meaning without committing the error of defining it".
} 
e da faculdade de julgar. Ela ministrou um curso que tratava das experiências políticas do século XX, no qual os alunos tinham de elaborar uma biografia imaginária de alguém nascido na última década do século XIX. Com base nessas ideias e práticas da filósofa, cada uma das oficinas do ciclo foi idealizada em dois momentos, um reflexivo e outro criativo.

No momento reflexivo, os participantes tiveram contato com materiais representativos de situações violentas ou "de crise", por meio da leitura e debate de textos literários de autores como Margaret Atwood, Paul Celan, Marguerite Duras, William Gibson e George Orwell, entre outros, assim como trechos de filmes e trabalhos artísticos, além de um material teórico de Hannah Arendt, Jacques Derrida e Celso Lafer, com o qual se pretendia abrir diálogo com os textos literários propostos sem, contudo, fornecer uma explicação conclusiva ou final. No momento 72 criativo, os participantes tiveram a oportunidade de escrever textos literários cujo protagonista tivesse vivenciado alguma situação em que os direitos humanos estivessem em questão, exercitando, assim, os participantes, a capacidade de representação e de "sair em visita" a partir do olhar do outro.

Neste artigo, abordaremos (i) a base teórica utilizada para a concepção das oficinas, descrevendo brevemente o curso da Hannah Arendt em que foram inspiradas, (ii) o conteúdo teórico transmitido por uma aula expositiva, em vista do qual tanto o exercício reflexivo quanto o criativo deveriam ser realizados, (iii) a maneira como foram conduzidos os exercícios reflexivo e criativo, como estes se desenvolveram de fato, e finalmente (iv) refletiremos a respeito

\footnotetext{
3 Hannah Arendt definia momentos de crise ("when the chips are down") como aqueles em que os padrões morais e religiosos são colocados à prova, e não se pode mais depositar confiança nas regras e padrões pelos quais vivemos para pautar nossas ações.
} 
dos resultados das oficinas, assim como sobre seus produtos concretos, os textos dos alunos.

\section{O curso de Hannah Arendt}

Hannah Arendt tinha enorme preocupação com a memória do totalitarismo, uma vez que essa memória e sua compreensão poderiam evitar que um evento das proporções do holocausto viesse a ocorrer novamente. Nesse sentido, Arendt sempre atribuiu grande importância à narrativa e à experiência como meio de alcançar essa compreensão (Lafer, 2007, p. 289).

Por um lado, a narrativa seria de fundamental importância em tempos de crise, "numa época em que os universais do pensamento se tornaram fugidios" (Lafer, 2007, p. 289). Por meio da narratividade, os exemplos e a ação política são revelados, contados, seja pela ficção ou biografia ou pela própria história. Por outro lado, para Arendt, a narrativa não só revelaria os exemplos, como também possibilitaria vivenciarmos experiências, experiências estas que seriam a base para a própria faculdade de pensar, como ela esclarece no prefácio de Entre o passado e o futuro (Arendt, 2000). E foi refletindo sobre as dimensões do pensar, do julgar e da vida política que Hannah Arendt elaborou um curso para seus alunos, no qual as nossas oficinas se inspiraram.

Bem antes, um curso proferido por ela tomava a experiência e a história como centrais. Ocorrido no Fall Term de 1965, na Universidade de Cornell ${ }^{4}$, o curso de pós-graduação intitulado "Political experiences in the twentieth century", do qual Celso Lafer participara como aluno, comenta ele que, sem dúvida, é um dos trabalhos

\footnotetext{
4 Houve um curso que antecedeu a este no Spring Term de 1955, na Universidade da Califórnia, em Berkeley, intitulado "Contemporary issues"; e um desdobramento posterior: o curso de pós-graduação do Spring Term de 1968 na New School for Social Research, exatamente com o mesmo título do curso de Cornell.
} 
de Arendt mais citados, tendo sido utilizado pelo próprio Lafer (2007) como um de seus suportes teóricos.

Segundo Lafer (2007, p. 292), os cursos

[...] trataram das experiências políticas do século XX por meio da biografia imaginária de alguém que nasceu na última década do século XIX. A estória desse homem não é a de alguém que está à margem das coisas, apenas observando, mas não é, também, a de um grande ator protagônico [embora este vá agir como se o fosse].

Não podemos esquecer ainda que Hannah Arendt também gostava de contar histórias, como em seu livro Homens em tempos sombrios e na biografia de Rahel Varnhagen ${ }^{5}$. Ela não diferenciava entre aqueles que fazem a história e aqueles que a sofrem, uma vez que a medida do juízo do historiador não seria o êxito histórico-político. Por isso, ela escolhe 74 contar a história de Walter Benjamin, de Rosa Luxemburgo e não de Lênin, por exemplo.

Para a Arendt narradora, contadora de histórias, haveria outra maneira de escrever a história diferente daquela que caracteriza a relação do historiador com os fatos:

[...] a forma original de se contar uma história.

O significado de tais histórias é diferente dos significados grandiosos dos quais fala o historiador; não é um padrão e, por isso, dificilmente pode ser captado em uma frase. Pensamos aqui em uma história de vida, uma biografia. No que um homem poderia contar ou contaria quando fosse relatar sua história, e como ele destilaria, por assim dizer, a sua essência (Contêiner n ${ }^{\circ} 58$ - 023611, Arendt apud Lafer, 2007; tradução das autoras).

\footnotetext{
5 Rahel Varnhagen: the life of a Jewess (Baltimore, Maryland: The Johns Hopkins University Press, 2000).
} 
Dessa forma, no curso de Cornell, assim como no prefácio de Entre o passado e o futuro, Arendt vincula a atividade do pensar com o lembrar. Diz que todo evento que é lembrado, é pensado, assim sendo, o contar de uma história seria uma forma apropriada de pensá-la. É essa localização do pensamento - entre o passado e o futuro, entre lembrança e antecipação ${ }^{6}-$, que ainda não se conforma em teoria, que ela busca ao propor uma biografia imaginária no seu curso (Lafer, 2007, p. 295). Para Arendt, tanto no plano da compreensão do eu, da identidade, como no plano da compreensão do mundo, esses hiatos na existência, assim como na história, podem conter o momento da verdade ${ }^{7}$.

Essa hipotética biografia seria uma aproximação metafórica da consciência de uma pessoa que escapou do pensamento para a ação e, depois de ter agido, se viu impelida a retornar ao pensamento ${ }^{8}$. Ela propôs o resgate da "experiência de alguém que reagiu aos eventos que sobre ele incidiram" (Lafer, 2007, p. 292) e cujo destino foi determinado pela política, como ocorreu com ela mesma durante o nazismo.

O objetivo dessa biografia também era discutir em que medida as teorias contemporâneas são adequadas para lidar com as experiências centrais do século XX (Contêiner $n^{\circ} 57$ - 023764, Arendt apud Lafer, 2007). Nesse sentido, se pretendia evidenciar a inadequação do conhecimento tradicional, e da forma de se atingir esse conhe-

\footnotetext{
${ }^{6}$ Arendt (1961, p. 9) refere-se ao "intervalo de tempo que é totalmente determinado por coisas que não são mais e por coisas que não são ainda" (tradução livre das autoras).

7 A verdade aqui não pode ser entendida em sua acepção moderna e inequívoca como algo que se deduz do processo da história, tendo em vista que a própria Arendt (1961, p. 14), em outro momento, ressalta que os exercícios do pensamento e da compreensão põem em suspenso o "problema da verdade".

8 Movimento este descrito por Arendt (2000) também no prefácio de Entre o passado e o futuro, ao tratar da experiência do poeta René Char na resistência francesa.
} 
cimento, para a compreensão do ineditismo que caracterizou o século $\mathrm{XX}$, instigando seus alunos a pensarem e julgarem sem um parâmetro preestabelecido.

Conforme descrito por Lafer, a bibliografia do curso incluía romances, poesias, autobiografias, biografias, textos de cartas, transcrições de processos, entre outros. Os alunos deviam olhar para esses recursos como "o mergulho do pescador de pérolas que busca extrair das profundezas e trazer para a superfície o contorno das cristalizações que instigam o pensamento, unificando-os por meio de uma biografia imaginária” (Lafer, 2007, p. 295).

Com isso, Hannah Arendt buscava selecionar textos que representassem a realidade em sentido amplo e que, simultaneamente, instigassem a imaginação criativa. No tratamento dos textos, ela procurava "presentificar" para os alunos os acontecimentos e as experiências que estes não poderiam ter vivenciado, estabelecendo conexões 76 que em um primeiro momento não pareciam evidentes. Outro elemento importante de sua proposta era a ficção: os alunos deviam ter contato com muita ficção para que não recebessem a experiência nem em seu estado bruto, nem carregada de elaborações teoréticas (Contêiner $\mathrm{n}^{\circ} 57-023764$, Arendt apud Lafer, 2007). A partir daí, eles seriam convidados a "reviver" os eventos do século XX, para narrá-los no lugar de outro - "vicariously" (Lafer, 2007, pp. 296-97).

O curso exigia dos alunos fundamentalmente a capacidade de imaginação, essencial também para a compreensão, na obra de Arendt, do exercício da faculdade de julgar. A característica básica da imaginação para Arendt é "tornar presente o que está ausente"; e, ao tornar presentes, simultaneamente, o passado e o futuro, ela nos permite conceber soluções compreensivas para nossos dilemas individuais e do mundo em que vivemos. 


\section{Pressupostos teóricos para as oficinas}

A primeira oficina do ciclo foi dedicada a uma exposição de pressupostos teóricos que deveriam dar base às reflexões e ao exercício de escrita a serem realizados. Procuramos estabelecer uma relação entre a temática dos direitos humanos e a narrativa no pensamento de Hannah Arendt.

Abordamos, de início, a Declaração Universal dos Direitos Humanos como o documento que promoveu uma transformação, principalmente no que diz respeito à titularidade dos direitos humanos, que deixa de ser vinculada ao status de cidadão nacional e passa a ser vinculada aos seres humanos de forma abrangente, garantindo assim a tutela internacional ao direito a ter direitos ${ }^{9}$. Foi assim que começou efetivamente a ser restringida, em matéria de direitos humanos, a razão de Estado, e corroída a competência reservada da soberania dos governantes (Alves, 1994).

Em segundo lugar, a Declaração Universal teria realizado uma mudança significativa no que diz respeito à responsabilidade pela promoção e efetivação dos direitos humanos. Em vista da crítica de Marx aos direitos do homem e dos cida-

9 Considerando que a desnacionalização tornara-se uma poderosa arma totalitária, e a incapacidade constitucional dos Estados-nações europeus de proteger os direitos humanos dos que haviam perdido seus direitos nacionais, houve o surgimento de uma classe de indésirables, que tinham seus direitos humanos violados sob a afirmação dos movimentos totalitários de que não existiam direitos humanos inalienáveis. Nem a Liga das Nações, nem os Tratados das Minorias teriam evitado que os Estados assimilassem suas minorias mais ou menos à força. Durante a Segunda Guerra Mundial, a situação deteriorou-se ainda mais com os grupos de apátridas sendo enviados rotineiramente a campos de internação. A total implicação da identificação dos direitos do homem com os direitos dos povos no sistema europeu de Estado-nação só se tornou evidente no surgimento de um número inesperado e crescente de pessoas e povos cujos direitos eram precariamente salvaguardados: a perda dos direitos nacionais equivalia a um sentenciamento à perda dos direitos humanos. A primeira perda sofrida por essas pessoas era a perda do lar e a segunda era a perda da proteção legal em todos os países. É a partir daí que Hannah Arendt trata do "direito a ter direitos", que poderia ser expresso como a preservação da validade dos direitos humanos e da dignidade que eles outorgam, mesmo que um ser humano seja expulso da comunidade humana. É, antes de tudo, essa necessidade que a Declaração vem contemplar, garantindo respaldo legal universal. 
dãos da Revolução Francesa, realizada em A questão judaica, pensamos que a Declaração forneceria uma resposta a essa crítica, abolindo a barreira existente entre o Estado, como espaço exclusivo da atividade política, e a sociedade civil, como espaço de garantia de privilégios travestidos de direitos dos cidadãos.

Nesse sentido, a Declaração é endereçada não exclusivamente ao Estado, ou à garantia dos direitos dos cidadãos vinculados a ele, mas sim

[...] a todos os povos e todas as nações, com o objetivo de que cada indivíduo e cada órgão da sociedade, tendo sempre em mente esta Declaração, se esforce [...] por promover o respeito a esses direitos e liberdades, e, pela adoção de medidas progressivas de caráter nacional e internacional, por assegurar o seu reconhecimento e a sua observância universal e efetiva [...]" (ONU, 1948; grifos nossos).

Relativamente ao que motivou a proclamação da Declaração, motivação essa indissociável de seu objetivo final, destacamos que o preâmbulo do documento traz uma preocupação semelhante àquela expressa por Hannah Arendt no julgamento de Adolf Eichmann. O preâmbulo menciona que "o desrespeito e o desprezo pelos direitos humanos resultaram em atos bárbaros que ultrajaram a consciência da humanidade", referindo-se principalmente às atrocidades do totalitarismo cometidas ao longo da Segunda Guerra Mundial. Arendt (2006, p. 273), por seu turno, demonstra uma preocupação semelhante, a partir do julgamento de Eichmann, de que

[...] crimes similares possam ser cometidos no futuro.

[...] Faz parte da própria natureza das coisas humanas que cada ato que foi percebido e registrado pela história da humanidade fique com a humanidade como uma 
potencialidade [...] Nenhum castigo jamais possuiu poder dissuasório suficiente para impedir a perpetração de crimes ${ }^{10}$.

Diante dessa preocupação, a Declaração Universal não orienta, como era esperado, à ação legislativa, como se a Declaração constituísse um padrão a ser seguido nas legislações e codificações por todos os Estados membros das Nações Unidas $^{11}$, mas possui, em vez disso, um propósito educativo. Dessa forma, pode-se dizer que a Declaração de 1948 é proclamada como um padrão para os objetivos educacionais explícitos e para os objetivos legislativos nela implícitos.

Considerando o principal meio escolhido pelos redatores da Declaração para sua promoção e efetivação, pretendíamos no curso promover um diálogo entre o espírito da educação estabelecido no próprio documento, e em outros posteriores que tratam da educação em direitos humanos ${ }^{12}$, e as reflexões de Hannah Arendt acerca de como evitar que atos tão bárbaros e violentos quanto aqueles perpetrados no decorrer da Segunda Guerra se repetissem.

A partir de sua experiência no julgamento de Eichmann, Hannah Arendt começou a indagar-se sobre a raiz do mal incontestável dos atos do réu, cuja motivação não poderia ser retraçada em níveis mais profundos, nem em firmes convicções ideológicas. Segundo Arendt (1992, p. 6):

\footnotetext{
${ }^{10}$ Tradução livre das autoras aqui e em demais citações de obras em língua inglesa.

${ }^{11}$ Os redatores perceberam que seria melhor incorporar princípios relativos aos deveres dos Estados em um novo documento, mais apropriado para tal. Os instrumentos que cumpriram esse papel foram o Pacto Internacional dos Direitos Civis e Políticos e o Pacto Internacional dos Direitos Econômicos, Sociais e Culturais.

${ }^{12}$ Recomendação da Unesco (1974) sobre educação para entendimento, cooperação e paz internacionais e educação relacionada a direitos humanos e liberdades fundamentais; Plano de Ação Mundial da Unesco sobre a Educação para os Direitos Humanos e Democracia (Declaração de Montreal, 1993); Declaração e Plano de Ação de Viena (1993); Década das Nações Unidas para Educação em Direitos Humanos, proclamada em dezembro de 1994 pela Assembleia Geral; Programa Mundial para a Educação em Direitos Humanos (2005 - em curso); e Declaração sobre Educação e Treinamento em Direitos Humanos da Organização das Nações Unidas (2011).
} 
[...] a única característica notória que se podia perceber tanto em seu comportamento anterior quanto durante o próprio julgamento e o sumário de culpa que o antecedeu era algo de inteiramente negativo: não era estupidez, mas irreflexão. [...] Foi essa ausência de pensamento - uma experiência tão comum em nossa vida cotidiana, em que dificilmente temos tempo e muito menos desejo de parar e pensar - que despertou meu interesse.

Tendo o regime nazista introduzido um novo sistema de valores que negava amplamente os preceitos morais de outrora, demonstrou que, contanto que os padrões morais fossem aceitos socialmente e legitimados legalmente, eles seriam obedecidos não só por criminosos, mas também pelas pessoas comuns. Para Arendt, a solução desse impasse, a única forma de se lidar com um sistema de valores instável, no qual não se pode confiar para a tomada das decisões, está no exercício do pensamento e do julgamento.

Vale destacar, contudo, que o pensamento e julgamento arendtianos partem essencialmente do diálogo do eu consigo mesmo, da duplicidade do eu exigida por todo o pensamento, e do senso comum, "nosso órgão mental para perceber, compreender e lidar com a realidade e com os fatos" (Arendt, 1970, p. 8) ${ }^{13}$, não oferecendo uma resposta universal. Arendt afirma que os limites autoestabelecidos por essas atividades de pensar e julgar podem mudar consideravelmente de pessoa para pessoa, conforme

\footnotetext{
${ }^{13}$ Sendo o pensamento centrado principalmente na filosofia moral do eu, e do estar em acordo consigo mesmo, a faculdade de julgar tem o papel de equilibrar essa interioridade com o fato de ser no mundo, entre os homens, que realmente habitamos. Ela deduz essa faculdade do juízo de gosto kantiano. Kant aborda essa interação com os outros a partir do senso comum, sem o qual o homem não estaria preparado para a interação civilizada, que, por seu turno, depende da capacidade de imaginação e de representação, da capacidade de "sair em visita" ao outro. Segundo Arendt (2004, p. 207), "quanto maior for o número das posições de pessoas que posso tornar presentes no meu pensamento e, assim, levar em consideração no meu julgamento, mais representativo ele será".
} 
o lugar ou época em que se apresentam; no entanto, “o mal ilimitado e extremo só é possível quando essas raízes cultivadas a partir do eu, que automaticamente limitam as possibilidades, estão inteiramente ausentes" (Arendt, 2004, p. 166).

Dessa forma, segundo o diálogo que procurávamos estabelecer nas oficinas, entre a teoria dos direitos humanos e o pensamento de Hannah Arendt, a principal função da educação em direitos humanos talvez não fosse convencer acerca da validade universal de determinados preceitos, mas sim da não validade objetiva desses padrões per se.

\section{Propostas para a criação literária}

Dentro dessa moldura teórica apresentada, a prática da escrita encontrava-se no coração das oficinas ministradas pelo exercício da faculdade da imaginação é que se pode pensar em situações de crise, "when the chips are down".

Acreditamos ser importante, ao tratarmos especificamente dos momentos reflexivo e criativo das oficinas, apresentar o perfil dos alunos, resumido nas seguintes categorias: pesquisadores (alunos de pós-graduação, com destaque para ciências sociais, direito, letras e psicologia); jornalistas, procuradores e advogados (em sua maioria, ocupando cargos públicos ou em organizações sem fins lucrativos); professores (de universidades particulares e colégios públicos); estudantes de graduação (com destaque para direito). Ou seja, era de pessoas familiarizadas com o discurso sobre direitos humanos e que tinham muito prazer em ler e escrever. Entretanto, em uma mesma turma, podíamos encontrar pessoas com hábitos de escrita muito diferentes, desde escritores já publicados até aquelas que não haviam exercitado sua escrita autoral nos últimos anos, as quais relataram escrever prioritariamente artigos científicos e textos de caráter jornalístico ou jurídico. 
Vale destacar que a procura por vagas foi muito grande e não pudemos atender a todos os interessados, o que frisa a carência de cursos que francamente estimulem o lado criativo principalmente de estudantes no ensino superior.

Para o desenvolvimento do exercício reflexivo, as atividades trataram de colocar os alunos em contato com um corpus literário ${ }^{14}$ de gêneros diversificados, razoavelmente contemporâneo e complementado por vídeos e discussões, de modo a permitir interpretações e diversas chaves de leituras para se perceber a complexidade de situações que envolvem a violação de direitos humanos, especialmente em contextos de crise. Além disso, o material apresentado convidava os participantes a deslocarem-se de suas situações existenciais e individualidades linguísticas e saírem em visita de outros, enfatizando o valor do exemplo que mencionamos anteriormente.

Após essa etapa de sensibilização e discussão calcadas 82 principalmente em textos literários, foram sorteados quatro temas possíveis para elaboração do texto criativo - o grande desafio da oficina. Cada um dos alunos recebia uma reportagem simples a respeito de uma situação envolvendo alguma violação de direitos humanos. Diante do panorama, o exercício de criação foi planejado prioritariamente como uma incitação às faculdades de pensar e julgar - não foram enfatizados aspectos da criação pertencentes ao campo específico

\footnotetext{
${ }^{14}$ Houve variação na eleição desse material, mas foram: os poemas "A tristeza é como uma luz que arde no coração" (Arendt, trad. Antonio Transito, 1994), "Fuga da morte" (Celan, trad. Modesto Carone, 1964), "Distúrbio psicossomático, aliás, banzo" (Semog, Ogum's toques negros, org. Guellwaar Adún, 2014) e "Sobre a violência” (Brecht, trad. e org. Paulo César de Souza, 2012); em prosa, trechos das obras Homens em tempos sombrios (Arendt, 2008), O conto da Aia (Atwood, trad. Ana Deiró, 2006), La douleur (Duras, trad. Laura Mascaro, inédito), 1984 (Orwell, trad. Hubner e Jahn, 2009) e Neuromancer (Gibson, trad. Fabio Fernandes, 2008); em linguagem audiovisual, um trecho de Hiroshima mon amour (dir. Alain Resnais, 1959); o vídeo anônimo de 17 de junho No Rio, policial joga sua arma no fogo durante manifestação (não mais disponível) e o vídeo Letter to a refusing pilot, do artista libanês Akram Zaatari, disponível em: <http://www.youtube.com/watch?v=72p_j8dfXk8>; acessado em: 28 jul. 2015.
} 
da literatura, como a forma literária e seu aprimoramento. O essencial era o fazer, cumprir a jornada.

A proposta então era produzir um texto que dialogasse com aquele episódio. Vislumbrar outros pontos de vista possíveis, sair em buscar de novos olhares, contemplando a própria proposta do curso original de Arendt, de incitar os alunos a relatarem a "experiência de alguém que reagiu aos eventos que sobre ele incidiram" (Lafer, 2007, p. 292). Gênero e forma literários ficavam por escolha do aluno. Como houve um bom hiato entre a propositura do exercício e sua entrega, foi possível às turmas fazerem pesquisa, se envolverem nos fatos e histórias. Em cada proposta, residia um distanciamento: foram escolhidos fatos deslocados geograficamente e temporalmente e, na medida do possível, menos divulgados.

As quatro reportagens versavam sobre: (i) a ex-colônia Mirueira, que se situava na cidade de Paulista em Pernambuco, local de confinamento de pessoas com hanseníase, que eram separadas brutalmente de suas famílias e pertences; (ii) o caso da descoberta do passado de um casarão no bairro de Santa Efigênia em Belo Horizonte - entre 1947 e 1979, onde funcionou o Hospital de Neuropsiquiatria Infantil com episódios reiterados de tortura e maus tratos a crianças e adolescentes; (iii) o atual conflito no Sudão do Sul entre os grupos étnicos dinka e nuer; e (iv) a Épuration légale ("purga legal”) na França pós-Segunda Guerra Mundial, que compreendia a execração pública de mulheres que teriam se envolvido com alemães e outros combatentes do Eixo, com humilhações e tonsura, o corte de cabelos em público.

As produções foram bastante profícuas, os exercícios feitos com afinco. O envolvimento dos alunos com os temas deu-se com muita seriedade, fomentando pesquisas, discussões e análises. Considerando que a prática da criação literária é muito interessante para se refletir a respeito de 
temas geralmente tão abstratos quanto justiça e reparação, a indicamos como ferramenta útil e lúdica em sala de aula.

$* * *$

Para o fechamento deste artigo, foram selecionados dois textos de participantes - um em poesia, "Cupim na Mirueira de Recife", de Natália Ciotto dos Santos, e outro em prosa, "Colônia”, de Flávio Rodrigo Penteado -, elaborados a partir da mesma proposta: o caso da colônia pernambucana da Mirueira, para isolar pessoas com hanseníase. Ambos os textos dialogam claramente com a ideia de violação de direitos humanos - o silenciamento das vítimas, a falta de possibilidade de defesa, o isolamento forçado, a violência sem explicação, o apagamento da memória.

Assim, deixamos nossa contribuição para aplicar as ideias de Hannah Arendt, nas quais a narrativa contribuiria para o 84 exercício da mentalidade alargada, essencial para a faculdade de julgar e para o senso comum, que significaria tornar o outro e sua situação existencial presentes em nós mesmos, quando estes estão de fato ausentes. Na bonita colocação de Arendt, a poética ${ }^{15}$ não difere da filosofia, mas antes descreve o caminho do/para o pensamento (Weigel, 2009).

\section{Cupim na Mirueira de Recife \\ por Natália Ciotto dos Santos \\ Acordei manchada na pele. \\ Ele também. \\ Fomos levados juntos à colônia. \\ Mas fomos sozinhos à colônia e \\ Eles também.}

\footnotetext{
${ }^{15}$ Poética designa, para ela, não apenas as regras de produção do trabalho literário, mas o estudo mais amplo da potência representacional original da arte.
} 
Levei embrulhado

Dentro do pano de prato:

uma muda de roupa

Ele numa trouxa:

uma navalha, um sapato.

Eles arrastavam retratos, copos e terços.

Arrumaram em prateleiras tortas e poucas.

Nossos planos. Nós também.

Nós temos peles esfoladas, pontas tortas,

filhos pagando por nossos

pecados no preventório.

Temos filhos que nem sabemos se são nossos.

Temos feridas e filhos expostos.

Eles nos visitam e não nos tocam.

Eles nos visitam e não nos olham.

Acordei com uma mancha na pele.

E Recife também.

Não há lustra móveis que tire

as manchas de Mirueira.

E de nós também.

\section{Colônia}

por Flávio Rodrigo Penteado

Caia sobre eles a morte,

Desçam vivos ao túmulo, Pois o mal se aninha entre eles.

(SALMO 55)

Não sabe dizer desde quando vive ali. Quando acontece, eles vão e levam. No trajeto, dão trapos novos, um trocinho de toalha. Explicam a rotina. Logo passa, dizem - as lembranças, não as feridas. Lá chegando, a mesa posta, a casa limpa. Cada coisa em seu lugar. Organiza-se. A colônia como uma grande cidade. Funciona. 
Em volta, surgem casas, escolas, igrejas, rádio. Há quem diga ter visto delegacia, até prefeitura. É o que contam. Enxerga, mas não vê nem resquício de coisa alguma. Faz bem, dizem. Ajuda na cura das feridas - as da pele, não as de dentro. Ouve falar de famílias internadas juntas e de outros que, abrigados sozinhos, se obrigam a fazer vida nova, quem sabe casar, adotar novos costumes. Não sabe qual é seu caso. Força de lei, mudam-lhe os trocados em moedas envelhecidas. Medida preventiva, esclarecem, evita contaminação. Ali todo mundo é doente. Barbearia, cozinha, limpeza. Logo-logo se arranja, recheia seu caneco, dá rumo na vida. Não param de depositar gente ali. Suspeitam que, depois, vão e levam os parentes. Efeito da incubação, sorrateira: até seis anos para se manifestarem os primeiros sintomas. Não vê nenhum.

Aprende que o mal também se transmite pela palavra, em forma de saliva. Amputam-lhe a fala. Não vê sinal de pensamento.

Ali todo mundo é paciente. Infiltrações na face, mãos em garra, inchaço das orelhas: cada coisa em seu lugar. Não há pressa nem calendário, há existência.

Senhor, se queres, tens o poder de me purificar.

Não há Cristo que cure um corpo em fuga.

\section{Ana Rüsche}

é escritora e doutora pela Faculdade de Filosofia, Letras

e Ciências Humanas da Universidade de São Paulo (FFLCH-USP) .

\section{Laura Mascaro}

é coordenadora e pesquisadora do Centro de Estudos Hannah Arendt e doutoranda em Literatura Francesa na FFLCH-USP. 


\section{Bibliografia}

ALVES, J. A. 1994. Os direitos humanos como tema global. São Paulo:

Perspectiva.

ARENDT, H. 1961. Between past and future: Six exercises in political thought. New York: The Viking Press. 1968. Men in dark times. New York: Harvest Books. 1970. On violence. New York: Harvest Books. . 1987. Homens em tempos sombrios. Tradução de Denise Bottmann. São Paulo: Companhia das Letras. . 1992. A vida do espírito: o pensar, o querer, o julgar. Rio de Janeiro:

Relume Dumará/UFRJ. . 2000. Entre o passado e o futuro. 5. ed. Tradução de Mário W. Barbosa de Almeida. São Paulo: Perspectiva (coleção Debates, v. 64). . 2004. Responsabilidade e julgamento. São Paulo: Companhia das Letras. . 2006. Eichmann in Jerusalém: a report on the banality of evil.

London: Penguin Books. 2007. Eichmann em Jerusalém: um relato sobre a banalidade do mal. São Paulo: Companhia das Letras.

LAFER, C. 2007. "Experiência, ação e narrativa: reflexões sobre um curso de Hannah Arendt”. Estudos Avançados, v. 21, n. 60, pp. 289-304.

ONU. 1948. Declaração Universal dos Direitos Humanos. 10 dez. Disponível em: <http:/ / nacoesunidas.org/declaracao-universal-dos-direitoshumanos/>. Acesso em: 26 ago. 2015.

WEIGEL, S. 2009. "Poetics as a presupposition of philosophy: Hannah Arendt's. Denktagebuch". Telos, n. 146, pp. 97-110. 


\section{TORNAR PRESENTE 0 AUSENTE: ESCRITA CRIATIVA E REFLEXÃO SOBRE DIREITOS HUMANOS}

ANA RÜSCHE

\section{LAURA D. M. MASCARO}

Resumo: $\mathrm{O}$ artigo relata a experiência das oficinas "A Narrativa revela o sentido sem cometer o erro de defini-lo" sobre direitos humanos e criação literária ministradas pelas autoras atividades guiadas pelo pensamento filosófico de Hannah Arendt. A metodologia aplicada teve como inspiração o curso de Arendt "Experiências políticas no século XX" (ministrado em 1965), relatado por Celso Lafer no artigo "Experiência, ação e narrativa: reflexões sobre um curso de Hannah Arendt”. A criação literária mostrou-se uma poderosa ferramenta de reflexão sobre questões que envolvem direitos humanos, principalmente em momentos de crise.

Palavras-chave: Hannah Arendt; Escrita Criativa; Direitos Humanos.

\section{MAKING THE ABSENT PRESENT - A CREATIVE TOOL FOR A REFLECTION ON HUMAN RIGHTS}

Abstract: This article reports the experience of the workshops "Storytelling reveals meaning without committing the error of defining it" on human rights and creative writing taught by the authors - activities guided by the philosophical work of Hannah Arendt. The methodology was inspired by an Arendt's course entitled "Political experiences in the twentieth century" (1965), reported by Celso Lafer in the article "Experience, action and narrative: reflections on a course by Hannah Arendt". The creative writing has proved to be a powerful tool to the reflection on issues involving human rights, especially in times of crisis.

Keywords: Hannah Arendt; Creative Writing; Human Rights.

Recebido: 30/07/2015 Aprovado: 14/08/2015 